Revista de
Economild
Contemporâned

\title{
RAÚL PREBISCH E SEUS MANIFESTOS: MOMENTOS DE FORMAÇÃO DA CEPAL
}

\begin{abstract}
Bruno Borja ${ }^{a}$
${ }^{\text {a }}$ Professor da Universidade Federal Rural do Rio de Janeiro (UFRRJ). Pesquisador do Coletivo Marxista da Rural (MAR/UFRRJ) e do Laboratório de Estudos Marxistas (LEMA/UFRJ). Rio de Janeiro, RJ, Brasil. ORCID: https://orcid.org/0000-0002-4813-7001.

Recebido em 14 fevereiro 2019

Aceito em 08 julho 2020

RESUMO: Raúl Prebisch foi a principal liderança política e intelectual da Cepal, formulando as teses inaugurais do que viria a ser conhecido como estruturalismo latinoamericano. Passados 70 anos da publicação do primeiro estudo da Comissão sobre a América Latina, este artigo se propõe a sistematizar e analisar criticamente as formulações teóricas de Prebisch no momento de formação da Cepal. Após apresentar sua trajetória política e intelectual, serão analisados seus três primeiros documentos produzidos na comissão: O Desenvolvimento Econômico da América Latina e Alguns de seus Principais Problemas (1949); Crescimento, Equilíbrio e Disparidades: interpretação do processo de desenvolvimento econômico (1950); e Problemas Teóricos e Práticos do Crescimento Econômico (1951).
\end{abstract}

PALAVRAS-CHAVE: Raúl Prebisch; Cepal; estruturalismo latino-americano; sistema centro-periferia; América Latina.

CLASSIFICAÇÃO JEL: B20; B31; F02. 


\title{
RAUL PREBISCH AND HIS MANIFESTOS: MOMENTS OF THE FORMATION OF ECLAC
}

\begin{abstract}
Raúl Prebisch was the main political and intellectual leadership of Eclac. He formulated the inaugural theses of what would have come to be known as Latin American structuralism. After more than 70 years of publication of the Commission's first study on Latin America, the present article systematizes and analyzes critically Prebisch's theoretical formulations entangled in the formation of Eclac. After describing his political and intellectual trajectory, the paper analyzes the first three documents he produced as part of the Commission: The Economic Development of Latin America and Some of its Main Problems (1949); Growth, Balance and Disparities: Interpretation of the Economic Development Process (1950); and Theoretical and Practical Problems of Economic Growth (1951).
\end{abstract}

KEYWORDS: Raúl Prebisch; Eclac; Latin American structuralism; center-periphery system; Latin America. 


\section{INTRODUÇÃO}

Figura central, e controversa, da história do pensamento econômico latino-americano, Raúl Prebisch foi um dos intelectuais mais influentes do século XX na região, sendo a grande liderança política nos anos de formação da Comissão Econômica para América Latina e o Caribe (Cepal). Coordenou os primeiros estudos econômicos da comissão e redigiu documentos que marcariam época - como aquele publicado 70 anos atrás, em 1949, e que ganharia a alcunha de manifesto latino-americano.

É possível dizer que os trabalhos inaugurais de Prebisch na Cepal formam um conjunto de manifestos, um marco fundacional do estruturalismo latino-americano. Ali é esboçada a formulação do sistema centro-periferia, com destaque para a análise da dinâmica cíclica da economia mundial e de seus efeitos diferenciados entre centro e periferia. A força motora seria a tentativa do autor para dar fundamento teórico à observação empírica da deterioração dos termos de troca dos produtos primários da América Latina, assim como suas críticas à divisão internacional do trabalho e à política comercial dos EUA. Assim, Prebisch fará uma crítica ao falso sentido de universalidade da economia do desenvolvimento, colocando as peculiaridades do desenvolvimento latino-americano e abrindo um novo caminho de reflexão na região.

Este artigo se propõe a sistematizar e analisar criticamente essas formulações teóricas de Prebisch. Primeiro apresenta sua trajetória política e intelectual e, depois, perpassa seus três primeiros documentos produzidos na Cepal: O Desenvolvimento Econômico da América Latina e Alguns de seus Principais Problemas (1949); Crescimento, Equilíbrio e Disparidades: interpretação do processo de desenvolvimento econômico (1950) parte introdutória ao famoso Estudo Econômico da América Latina, 1949; e Problemas Teóricos e Práticos do Crescimento Econômico (1951).

\section{RAÚL PREBISCH: TRAJETÓRIA POLÍTICA E INTELECTUAL}

Nascido em Tucamán, província agrícola argentina, Raúl Prebisch (1901-1986) é considerado por muitos o maior economista latino-americano do século XX. Sua trajetória ilustra bem as mudanças da região nesse período: a princípio com posições liberais nos anos 1920, adota políticas anticíclicas nos anos 1930, transforma-se em paladino da industrialização periférica nos anos 1940 e 1950, mostra-se cético da forma concreta que tomou a substituição de importações nos anos 1960, e se revela crítico do sistema capitalista nos anos 1970. Tais inflexões em seu pensamento e na sua conduta política deram a Prebisch o caráter distintivo de ser um intelectual de renome internacional, diretor de grandes instituições e indicado ao Prêmio Nobel, mas criticado em seu país, 
inclusive impedido de receber o título de doutor honoris causa na Universidade de Tucumán (FONSECA, 2011).

Chega a Buenos Aires com 17 anos e se forma em contabilidade, demonstrando acentuado corte neoclássico em sua concepção de economia. Nos anos 1920, dá aulas na universidade, faz trabalhos de assessoria para a Sociedade Rural argentina, o Ministério da Fazenda e o Ministério da Agricultura, e torna-se diretor do Departamento Nacional de Estatísticas e do Banco de la Nación (BARBOSA, 2012). Convidado a assumir a subsecretaria da Fazenda após o golpe militar de 1930, recomendou políticas antiinflacionárias ortodoxas. Em 1932, torna-se membro da Comissão Preparatória da Conferência Econômica Mundial da Liga das Nações e, em 1933, participa da missão comercial argentina para assinar o Pacto Roca-Runciman com os ingleses - na Inglaterra, leu os artigos de Keynes publicados em jornal.

O grande feito de Prebisch na condução da política econômica argentina foi a criação e a direção do Banco Central da Argentina entre 1935 e 1943. Formou o banco com autonomia em relação ao governo, compondo uma diretoria com marcante presença de bancos privados nacionais e internacionais. Sua condução da política monetária durante a crise dos anos 1930, enfrentando a inflação e o desequilíbrio externo argentino, conferiu-lhe prestígio entre economistas e políticos da América Latina. No entanto, com a ascensão de Perón à presidência, foi afastado do cargo, sob acusação de operar em benefício de interesses estadunidenses (FONSECA, 2011).

Como o próprio Prebisch (1983) apontou, foi a grande crise dos anos 1930 que o fez mudar suas posições teóricas, impactadas pelas propostas de Keynes. Saindo do Banco Central, voltou a lecionar economia na Universidade de Buenos Aires, assumindo os cursos de dinâmica econômica e economia política. É um período de reflexão sobre sua experiência política durante a crise e de consultoria aos governos latino-americanos interessados em constituir bancos centrais. Segundo Rodríguez (1981), foi no México, em 1946, numa reunião de técnicos dos Bancos Centrais da região, que lançou a ideia do sistema centro-periferia. Na universidade, reflete sobre o ciclo econômico, influenciado também por Schumpeter e, em 1947, escreve Introdução a Keynes, primeiro livro de divulgação de seu pensamento na América Latina (COUTO, 2007).

Foi na condição de eminente economista que Prebisch chegou à Cepal em 1949 para uma consultoria com prazo determinado - somente após a conferência de 1950, em Montevidéu, assumiria a secretaria executiva. Seu trabalho na Comissão ganhou destaque internacional através de três textos considerados por diversos comentadores como inaugurais do estruturalismo latino-americano: ${ }^{1}$ O Desenvolvimento Econômico 1 Dentre os comentadores que sustentam essa opinião estão: Bielschowsky ([1988] 2000a, 2000b, 2011),
Furtado ([1985] 1997), Gurrieri ([1982] 2011) e Rodríguez (1981, 2009). 
da América Latina e Alguns de seus Principais Problemas (1949); Crescimento, Equilíbrio e Disparidades: interpretação do processo de desenvolvimento econômico (1950) - parte introdutória ao famoso Estudo Econômico da América Latina, 1949; e Problemas Teóricos e Práticos do Crescimento Econômico (1951).

Neles está o conteúdo básico do sistema centro-periferia desenvolvido por Prebisch, que subsidiou a formação de uma teoria do subdesenvolvimento na Cepal. Apresentam a peculiaridade da periferia primário-exportadora frente ao centro industrializado do mundo, lançando suas tendências especificas à deterioração dos termos de intercâmbio, ao desequilíbrio do balanço de pagamentos e ao desemprego. A proposição geral da necessidade da industrialização para superar a condição periférica se alinha à ideologia das burguesias industriais em ascensão nos maiores países da América Latina, alcançando grande influência nos governos da região.

Suas críticas à divisão internacional do trabalho, ao liberalismo da periferia e à política protecionista dos EUA renderam tanto prestígio na região quanto a oposição deliberada dos EUA à Cepal. A criação da Comissão na ONU, em 1948, previa uma avaliação de sua continuidade três anos depois. Segundo Furtado ([1985] 1997), na conferência do México, em 1951, a delegação dos EUA mobilizou todas as forças no sentido de encerrar os trabalhos da Cepal e foi o apoio decidido do governo brasileiro, na presidência de Getúlio Vargas, que conseguiu sustentá-la.

Traduzidos por Furtado logo após sua conclusão, os dois primeiros textos de Prebisch foram publicados na Revista Brasileira de Economia e tiveram grande repercussão no Brasil, contando com a simpatia de representantes do governo, da Federação das Indústrias do Estado de São Paulo (FIESP) e da Confederação Nacional da Indústria (CNI). No início dos anos 1950, Prebisch participaria ativamente da controvérsia sobre desenvolvimento no Brasil, fazendo palestras na Fundação Getúlio Vargas e publicando textos de defesa do planejamento - opondo-se ao liberalismo de Eugênio Gudin e ao monetarismo de Otávio Bulhões, e confrontando outros economistas liberais de renome internacional que passaram pelo Brasil, como Jacob Viner.

Na segunda metade dos anos 1950, Prebisch colaboraria com a junta militar que depôs Perón do governo argentino, aplicando políticas ortodoxas na contenção da inflação encaminhando, segundo Furtado ([1985] 1997), uma inflexão na própria Cepal. Na década de 1960, faria uma revisão crítica da substituição de importações na América Latina, afirmando sua insuficiência dinâmica para absorver o excedente de trabalhadores e defendendo a necessidade de um mercado comum na região. Ainda nesta década, figura como um dos principais responsáveis pela criação da Associação Latino-Americana de Livre Comércio (Alalc), em 1960; da Aliança para o Progresso (programa dos EUA para o desenvolvimento da América Latina), em 1961; do Instituto Latino-Americano de 
Planificação Econômica e Social (Ilpes, órgão da Cepal), em 1962; e da Conferência das Nações Unidas sobre Comércio e Desenvolvimento (Unctad), em 1964.

Já nos anos 1970, segundo suas palavras (PREBISCH, 1981), faria um "giro ideológico" para criticar o sistema capitalista em artigos publicados na Revista de la Cepal, criada e dirigida por ele em 1976. Ali proporia uma síntese entre socialismo e liberalismo, mantendo o livre mercado, mas adotando um uso social do excedente econômico. Essa última etapa de seu pensamento, reunida em 1981 no livro Capitalismo Periférico - crisis e transformación, explicita as contradições presentes em suas formulações teóricas e em sua atuação política.

\section{O DESENVOLVIMENTO ECONÔMICO DA AMÉRICA} LATINA E ALGUNS DE SEUS PRINCIPAIS PROBLEMAS

Após ter seu nome descartado para uma vaga no Fundo Monetário Internacional (FMI), Prebisch foi encaminhado à Cepal, chegando a Santiago do Chile em fevereiro de 1949 (BARBOSA, 2012). A Comissão respondia aos anseios latino-americanos por um auxílio dos EUA e estava fadada a ser uma instituição burocrática e sem grande significado real. Prebisch chega para uma consultoria de três meses, com objetivo de produzir um documento sobre as economias da região e apresentá-lo na Conferência de Havana em maio de 1949. O Desenvolvimento Econômico da América Latina e Alguns de seus Principais Problemas, considerado por muitos o "manifesto latino-americano", questionava o falso sentido de universalidade ${ }^{2}$ da teoria econômica vigente, em especial a teoria das vantagens comparativas que justificava a divisão internacional do trabalho, colocando de forma explícita a peculiaridade da condição periférica.

Segundo Furtado ([1985] 1997), o texto foi redigido sem qualquer diálogo com os demais membros da Cepal, aproveitando o acúmulo de Prebisch na condução da economia argentina e na assessoria de outros países da região. Parte da constatação empírica da deterioração dos termos de troca dos países primário-exportadores durante a crise mundial dos anos 1930 e da percepção de que a especialização produtiva nos marcos da divisão internacional do trabalho não gerava a convergência dos níveis de renda, como defendia a teoria tradicional, mas, ao contrário, implicava um desenvolvimento desigual, com ampliação das diferenças de renda per capita.

Em 1949, quando ainda se consolidava a nascente economia do desenvolvimento, Prebisch dá um novo sentido ao atraso latino-americano, propondo a existência de um

\footnotetext{
2 “[...] uma das maiores falhas da teoria econômica geral, quando contemplada da periferia, é o seu falso sentido de universalidade" (Prebisch, [1949] 2011, p. 149, nota 1).
} 
sistema centro-periferia. ${ }^{3}$ Nesse sistema econômico mundial integrado, os centros industriais são o núcleo dinâmico do aumento de produtividade via progresso técnico, e seu dinamismo se propaga para a periferia através da demanda por bens agrícolas. A constatação empírica da piora na relação de preços entre bens industriais e primários ia contra o princípio geral da teoria das vantagens comparativas de que a maior produtividade da indústria tenderia a reduzir o preço de seus produtos, gerando uma melhora relativa na renda da periferia. Assim, a conjugação de maior produtividade com maiores preços nos centros industriais levou Prebisch a concluir que esses países não só se apropriavam das vantagens de seu progresso técnico, como ainda se apropriavam dos frutos do progresso técnico da periferia, pela redução relativa dos preços da exportação primária.

A causa disso deveria ser buscada no movimento cíclico da economia capitalista mundial, puxado pelo centro industrial. Na crescente cíclica, os preços primários subiriam mais que os preços industriais, mas na minguante, a redução seria ainda maior, conformando uma tendência à queda dos preços primários. Nesse documento, Prebisch centra a análise da deterioração dos termos de troca no diferente grau de organização dos trabalhadores no centro e na periferia, afirmando que na crescente cíclica os trabalhadores do centro conquistam aumentos salariais e na minguante conseguem defender os salários, retendo parte do aumento. A resistência à diminuição dos salários no centro seria transferida pelos empresários industriais para a periferia, onde os trabalhadores, sem a mesma organização, não resistiriam à redução de seus salários, com consequente queda nos preços de exportação.

A capacidade maior das massas dos centros cíclicos para obter aumentos de salários na crescente e defender seu nível na minguante e a aptidão desses centros para deslocar, graças ao papel que desempenham no processo produtivo, a pressão cíclica para a periferia - obrigando-a a comprimir sua renda mais intensamente do que nos centros - explicam por que, persistentemente, a renda nestes tende a subir mais intensamente do que nos países da periferia, como é evidente na experiência da América Latina. Nisso está a chave do fenômeno pelo qual os grandes centros industriais não apenas retêm para si o fruto da aplicação das inovações técnicas em sua própria economia, mas se encontram também em posição favorável para captar uma parte do fruto do progresso técnico da periferia. (PREBISCH, [1949] 2011, p. 108)

\footnotetext{
Embora ainda persistam nesse documento expressões típicas da ideologia do progresso, como "países novos" ao se referir à América Latina e uma alusão à "maturidade econômica" dos EUA. Esse debate sobre a ideologia do progresso e a perspectiva do atraso é apresentado com mais detalhe em Borja (2013).
} 
Ao apontar na luta dos trabalhadores por melhores salários no centro a causa da deterioração dos termos de troca da periferia, Prebisch explicita sua visão de mundo, alinhada à burguesia industrial, ignorando o conflito distributivo capital-trabalho. Coerente com essa postura política, o único meio indicado pelo autor para que a América Latina conseguisse reter os frutos do progresso técnico era a industrialização. No entanto, a substituição da Inglaterra pelos EUA como centro cíclico principal teria agravado ainda mais a situação da periferia, uma vez que este país apresentava uma contínua redução de seu coeficiente de importações e adotava políticas protecionistas para sua agricultura. A diminuição relativa das importações dos Estados Unidos significava uma escassez de dólares para a periferia, num momento em que a industrialização demandava uma importação crescente de bens de capital e em que o aumento de renda modificava o consumo da população em favor dos bens industriais importados. Tal escassez de dólares num contexto de aumento da demanda de importações dos EUA implicava uma tendência persistente ao desequilíbrio externo na América Latina.

A forma de atuação do novo centro cíclico principal durante a crise dos anos 1930 exerceu uma atração sobre o ouro e a moeda circulante na economia mundial: sua contração de renda na minguante cíclica se transferiu para os demais países via redução das importações (segundo Prebisch, uma forma normal de atuação do centro cíclico). No entanto, diferentemente da experiência inglesa, houve também uma redução significativa do coeficiente de importações, isso é, da demanda por importações em relação à renda. Tais efeitos somados - uma renda menor nos EUA e uma demanda de importações menor em proporção à renda - com uma interrupção simultânea dos empréstimos externos geraram uma aguda escassez de dólares na América Latina, difundindo na região o controle de câmbio para redirecionar suas importações. Prebisch considera a redução do coeficiente de importações dos EUA o problema fundamental do comércio exterior. Em função disso, a periferia se viu obrigada a reduzir também seu coeficiente de importações, optando pelo controle de câmbio e iniciando, na perspectiva do autor, um processo espontâneo de industrialização substitutiva. ${ }^{4}$

Tal industrialização sofreria com o círculo vicioso da condição periférica para a formação de capital: a margem de poupança para investimento é baixa porque depende da produtividade do trabalho, mas a produtividade é baixa porque falta capital aplicado na produção, isso é, a margem de poupança é baixa para investir. Apesar da grande 4 Ao argumentar por um processo espontâneo de substituição de importações, Prebisch incorre na natura-
lização da industrialização, mistificação típica da visão de mundo da burguesia industrial. 
influência de Keynes, Prebisch segue o raciocínio clássico da lei de Say para ver uma contradição entre investimento e consumo, ou seja, se há muito consumo, não há poupança para investir (SERRANO; MEDEIROS, 2004). Logo, defende o controle de câmbio e a taxação do consumo dos grupos de altas rendas para direcionar essa renda para poupança e para o investimento. No caso do comércio exterior, prioriza a importação de bens de capital que possibilitem a redução do coeficiente de importações e uma mudança em sua composição, junto a um aumento das exportações. Além disso, também apoia a entrada de capital estrangeiro para romper o círculo vicioso da formação de capital sem reduzir o consumo das massas, contanto que esse capital seja direcionado para investimentos que aumentem a produtividade do trabalho e a margem de poupança.

Embora o caminho de superação da condição periférica passe pela industrialização por substituição de importações, o autor destaca alguns limites desse processo. O primeiro seria a relação entre industrialização e produção primária para exportação. Como dito, para industrializar a periferia seria necessário alterar o coeficiente e a composição das importações, mas a disponibilidade de divisas depende das exportações, assim, haveria de se buscar um balanço entre industrialização e produção primária para exportação. Outro limite seria a dimensão ótima da empresa em relação à fragmentação dos mercados latino-americanos, demandando uma ação conjunta e complementar dos países no sentido da integração comercial.

De acordo com essa caracterização geral, Prebisch vai apresentar as bases para uma política anticíclica de manutenção do emprego nas economias da região. Embora tome o ciclo como a forma de crescer da economia capitalista mundial, exigindo uma teoria de conjunto, o autor introduz uma diferenciação da dinâmica cíclica no centro e na periferia. No centro, o papel dinâmico no movimento cíclico compete ao investimento, enquanto na periferia esse papel cabe às exportações. Ocorre que a principal variável definidora do volume de exportações é a renda dos países centrais, estando fora do alcance da política anticíclica da periferia.

No mundo do pós-guerra, quando foram criadas diversas organizações multilaterais, Prebisch aposta na cooperação internacional das entidades de crédito para levar a frente uma política anticíclica na periferia. O fornecimento de crédito na baixa cíclica da economia mundial serviria para resolver dois problemas inerentes aos países primárioexportadores em processo de industrialização substitutiva: primeiro, financiaria a compra de excedentes de produtos primários; e, segundo, garantiria a manutenção das importações de bens de capital necessários à industrialização. Assim, seria evitado o desemprego na produção primária e se garantiria a expansão da indústria, com consequente absorção de trabalhadores em níveis maiores de produtividade. 


\section{CRESCIMENTO, DESEQUILÍBRIO E DISPARIDADES:} INTERPRETAÇÃO DO PROCESSO DE DESENVOLVIMENTO ECONÔMICO

Apresentado na Conferência de Montevidéu em 1950 como introdução ao Estudo Econômico da América Latina 1949, este documento traz uma reformulação das propostas contidas no "manifesto" do ano anterior, avançando em alguns pontos. A crítica à divisão internacional do trabalho ganha substância, num confronto aberto ao liberalismo praticado na América Latina e à política comercial dos EUA, com sua primeira defesa clara do protecionismo da indústria periférica. Se por um lado esse trabalho consolidou o prestígio e a liderança de Prebisch na Cepal, alçando-o à condição de secretário executivo, por outro despertou a reação da delegação estadunidense, que se mobilizaria para tentar dissolver a comissão (FURTADO, [1985] 1997).

Tomando como horizonte histórico a revolução industrial inglesa do século 18, o autor afirma que a propagação universal do progresso técnico, dos países que o geraram para o resto do mundo, foi lenta e irregular. Daí se consolidaram um centro industrial e uma periferia vasta e heterogênea, com pouca participação nos aumentos de produtividade proporcionados pelas novas técnicas, exceto na produção de alimentos e matérias-primas destinados à exportação. ${ }^{5}$ Foram as dificuldades impostas ao comércio internacional pelos conflitos mundiais e pela grande depressão que lançaram a América Latina numa nova fase do processo de difusão universal da técnica, alterando seu modelo de desenvolvimento com a industrialização.

[...] o desenvolvimento econômico dos países periféricos é mais uma etapa do fenômeno de difusão universal das novas formas da técnica de produção ou, caso se prefira, do processo de desenvolvimento orgânico da economia do mundo. Antes da Primeira Guerra Mundial já haviam surgido, nos países de produção primária, algumas manifestações incipientes dessa nova etapa. Porém foi preciso que se apresentassem, como consequência do primeiro conflito bélico mundial, grandes dificuldades de importação para que os fatos fizessem evidentes as possibilidades industriais daqueles países, e que depois a grande depressão econômica dos anos 1930 comprovasse a convicção de que era preciso aproveitar tais possibilidades para compensar assim, mediante o desenvolvimento a partir de dentro, a notória insuficiência do impulso externo que até então tinha estimulado a economia latinoamericana. Uma comprovação que foi confirmada durante a Segunda Guerra

\footnotetext{
Embora trace um panorama geral para a região, Prebisch ressalta constantemente em todos seus trabalhos a especificidade de cada país. Nesse documento, ensaia uma primeira tipologia dos países de acordo com o tipo de produção para exportação e o volume de trabalhadores ocupados na atividade primária, influenciando diversas outras tipologias elaboradas no pensamento latino-americano.
} 
Mundial, quando a indústria da América Latina, não obstante todo o seu improviso e suas dificuldades, transformou-se em fonte de emprego e de consumo para uma parte considerável e crescente da população. (PREBISCH, [1950] 2011, p. 154)

Prebisch ressalta, contudo, que essa nova etapa tem início sem que os novos processos produtivos tenham sido plenamente assimilados na agricultura, restritos à produção para exportação, subsistindo regiões pré-capitalistas na economia. À medida que se difunde a técnica na agricultura, aumentando a produtividade do trabalho, cria-se um excedente de trabalhadores no campo que deve ser absorvido pelas atividades industriais, mas como não há plena mobilidade de fatores na economia mundial, não se deve esperar que a indústria do centro absorva os trabalhadores da periferia, colocando-se a necessidade da industrialização periférica. Como apresentado anteriormente, esse excedente de trabalhadores nas atividades primárias pressiona salários e preços para baixo e é um dos fatores determinantes da deterioração dos termos de troca. ${ }^{6}$ A crise mundial descortinara a dupla insuficiência do impulso externo da exportação primária, tanto para absorver produtivamente a população quanto para ampliar a capacidade para importar. A industrialização periférica, contraditoriamente, impõe o aumento do coeficiente de importações pela maior demanda por bens de capital e pelo aumento de renda transformado em maior demanda de artigos de consumo importados. Frente à crescente elevação do coeficiente de importações, a restrita capacidade para importar confirma uma tendência ao desequilíbrio do balanço de pagamentos na periferia. O tema da restrita capacidade para importar já havia sido tratado no documento de 1949, mas agora o autor aprofunda a análise, apontando um crescimento do volume de exportações abaixo do crescimento populacional na América Latina nos anos 1930 e 1940, agravado pela deterioração dos termos de troca.

Para essa situação, em muito contribui a atuação do novo centro cíclico principal, se comparada à do antigo centro inglês: segundo os dados do autor (PREBISCH, [1950] 2011), no período 1870-1913, a Grã-Bretanha tinha, em média, um coeficiente de importação de 32,1\% e um coeficiente de exportação de 18,9\%; já os EUA baixaram seus respectivos coeficientes de 5,82\% e 6,69\% no período $1925-1929$ para 2,95\% e $5,27 \%$ no período 1945-1949. O diferente grau de abertura dos centros cíclicos ao comércio externo determinava uma dinâmica distinta na economia mundial, acentuando a concentração de ouro no centro e inviabilizando o funcionamento regular do sistema

6 O autor usa mais uma vez o argumento keynesiano da resistência à queda dos salários no centro para analisar a dinâmica cíclica da economia mundial e a transferência da pressão sobre preços e salários para a periferia na minguante do ciclo. O que, potencialmente, mobiliza as forças sociais da América Latina contra os trabalhadores dos países centrais em sua luta por melhores salários. 
monetário internacional baseado no padrão ouro, isso é, criando a escassez de dólares na periferia. A precedência dinâmica da indústria sobre a agricultura, corroborando a deterioração dos termos de troca, obriga os países periféricos a reduzirem o valor de sua produção primária nas depressões cíclicas. A desvalorização monetária é uma tentativa de adequação à diminuição da demanda dos centros, estendendo à população as consequências do reajuste que recairia exclusivamente sobre os lucros de exportação. ${ }^{7}$

Para o autor, somente uma decidida industrialização que absorvesse o excedente de trabalhadores da agricultura poderia reverter, pela elevação dos salários, a tendência à deterioração dos termos de troca, evitando maior disparidade dos níveis de renda. No entanto, o enorme distanciamento entre o avançado desenvolvimento capitalista dos grandes centros industriais e o estágio pré-capitalista de parte da economia latinoamericana dava características peculiares à industrialização periférica. $\mathrm{O}$ contínuo progresso industrial no centro consolidou uma técnica produtiva com alta densidade de capital por trabalhador e propícia à produção em larga escala. Se, no centro, isso foi galgado paulatinamente a partir da base histórica do artesanato e em correspondência ao aumento de produtividade e renda, na periferia, a tentativa de industrialização tardia requer a introdução dessa técnica produtiva sem a referida correspondência dos níveis de produtividade e renda, explicitando uma escassez de poupança para a formação de capital e uma baixa intensidade de demanda para a produção em larga escala.

Além de aprofundar esses temas do documento anterior, Prebisch apresenta outro elemento peculiar à condição periférica: a ausência da indústria de bens de capital. Anteriormente vista somente pelo ângulo do crescente coeficiente de importações, a indústria de bens de capital vai ser analisada agora como uma fonte de emprego alternativa à produção primária. Se o progresso técnico traz consigo desemprego, no centro esse desemprego foi absorvido pela própria expansão da indústria de bens de capital. Já na periferia, a ausência dessa indústria não permite a absorção dos trabalhadores tornados excedentes pelo aumento da produtividade no campo. A demanda por bens de capital na periferia é transferida para o centro, potencializando sua absorção de trabalhadores com altos níveis de produtividade e salário.

A difusão do progresso técnico para a América Latina apresenta, portanto, certas características específicas [...]. Em resumo, se a meta fundamental de elevar a produtividade, por um lado, oferece a conhecida vantagem de se valer da experiência

Aqui Prebisch esboça uma ligação entre flutuação cíclica, desequilíbrio externo, desvalorização cambial e inflação, mas não desenvolve plenamente o tema. Essa será uma das principais contribuições de Celso Furtado na análise da economia brasileira, sintetizada no conceito de socialização das perdas (FURTADO, 1950, [1959] 2003). 
dos grandes países e evitar suas tentativas e erros, depara-se, por outro, com uma série de obstáculos originados do fato natural de os países que primeiro se desenvolveram estarem mais adiantados em renda, produtividade e capitalização. Do que se pode afirmar, de um modo um tanto paradoxal, que a elevada produtividade dos grandes países industriais constitui um dos maiores impedimentos que os países da periferia devem contornar para atingir produtividade semelhante. (PREBISCH, [1950] 2011, p. 230)

Tais características peculiares ao desenvolvimento periférico são agravadas ainda mais pelas políticas protecionistas adotadas nos países centrais. Prebisch afirma que a tentativa de Estados Unidos e Inglaterra de defenderem seus níveis de renda através de proteção tarifária, restrições à importação e subsídios à indústria e, principalmente, à agricultura, são obstáculos crescentes ao desenvolvimento industrial da periferia. Portanto, uma vez que os países de altas rendas tomam medidas para evitar a concorrência dos países de baixa renda na produção primária, estes países, por sua vez, devem praticar políticas protecionistas para garantir sua industrialização. Conclui que o desenvolvimento desigual do progresso técnico e a apropriação desigual de seus frutos apresentam problemas aos países periféricos que não podem ser resolvidos de modo espontâneo pelo livre jogo das forças econômicas, exigindo protecionismo.

\section{PROBLEMAS TEÓRICOS E PRÁTICOS DO CRESCIMENTO ECONÔMICO}

A Conferência do México, realizada em 1951, deveria selar o destino da Cepal, já que sua criação em 1948 previa uma ratificação três anos depois. Segundo Furtado ([1985] 1997), o Departamento de Estado dos EUA promoveu uma campanha diplomática para o encerramento de suas atividades, que destoavam do dócil alinhamento seguido pela Organização dos Estados Americanos (OEA). Num momento de escalada da guerra fria, com o início da guerra da Coreia, não convinha o funcionamento de uma comissão da ONU que havia conquistado tal grau de autonomia e influência política na América Latina, a ponto de seu secretariado criticar abertamente a política comercial dos Estados Unidos e propor o protecionismo da indústria na região. Foi a intervenção decidida da delegação brasileira, com apoio do presidente Getúlio Vargas, que articulou a resistência, garantindo a continuidade da comissão - o que valeu, inclusive, uma visita de agradecimento de Prebisch e Furtado ao presidente no Palácio do Catete antes de retornarem à sede da Cepal, em Santiago do Chile (FURTADO, [1985] 1997).

O documento Problemas Teóricos e Práticos do Crescimento Econômico foi apresentado nesse clima de disputa, mas manteve a orientação geral que Prebisch vinha adotando em seus trabalhos. Dando um passo além, propunha uma política de intervenção estatal e planejamento da industrialização periférica: um planejamento 
amplo que coordenasse protecionismo, industrialização substitutiva e desenvolvimento balanceado entre indústria e agricultura de exportação. Também merecem destaque a nova versão sobre a deterioração dos termos de intercâmbio, uma primeira crítica passageira ao regime de posse da terra e a distinção entre interesse do empresário e interesse geral na introdução de novas técnicas produtivas.

$\mathrm{Na}$ avaliação do autor, a mudança no modelo de desenvolvimento observada no entre guerras significou também uma mudança de objetivos: se antes o desenvolvimento buscava satisfazer a necessidade de bens primários dos centros industriais, agora o propósito fundamental passa a ser ampliar o nível geral de consumo da periferia a famosa distinção entre o modelo de desenvolvimento para fora e para dentro. Altera-se, com isso, o papel da tecnologia, que deixa de penetrar exclusivamente na produção para exportação e se estende à produção para o mercado interno, adaptando as técnicas produtivas elaboradas nos países centrais. A atuação do investimento estrangeiro sofre alteração consequente, deixando de ser o elemento principal de capitalização da exportação primária para ser um elemento suplementar no esforço de poupança interna dos países periféricos para elevar o consumo das massas.

Como visto em outros documentos, contrapõe-se consumo e poupança para investimento, afirmando ser incompatível o esforço de capitalização com a reprodução do estilo de vida dos países mais desenvolvidos através da importação. Defende-se que sejam contornados certos meios de publicidade e instigação ao consumo, para dar prioridade à importação de bens indispensáveis ao desenvolvimento. A substituição de importações não deve ser confundida com autarquia ou redução absoluta das importações: trata-se, antes, de uma mudança em sua composição de acordo com a capacidade para importar, objetivando estimular o desenvolvimento econômico.

Estender a técnica moderna a toda economia periférica requer um alto grau de capitalização - que, para Prebisch, deve ter origem na poupança interna e ser comandado pelo investimento nacional, tendo o capital estrangeiro um papel complementar, especialmente através de instituições internacionais de financiamento entre Estados. Dada a escassez de capital, seria preciso traçar um programa de desenvolvimento coordenado pelo Estado, ${ }^{8}$ a fim de otimizar a alocação de recursos

8 O autor propõe mesmo que a Cepal atue junto aos governos latino-americanos para formulação e execução dos programas de desenvolvimento: “A organização da Cepal poderia ser o campo mais propício para fazê-lo e para utilizar os resultados assim obtidos, bem como os conhecimentos colhidos por seus economistas na realidade latino-americana, na tarefa de formar grupos seletos de especialistas nos problemas de desenvolvimento econômico, na formulação e na execução dos respectivos programas" (PREBISCH, [1951] 2011 , p. 263). Isso de fato ocorreu, a partir de 1952, com a criação do programa de treinamento em problemas de desenvolvimento econômico, curso ministrado pela comissão, sob a direção de Jorge Ahumada (FURTADO, [1985] 1997). 
para obter o maior produto possível com o capital disponível - numa típica concepção neoclássica de planejamento.

O sistema tributário teria um papel de destaque na política de desenvolvimento, taxando altas rendas e certas formas de consumo, visando aumentar a capitalização privada e os recursos disponíveis para intervenção estatal - entendida como um meio de redistribuição de renda e de incentivo à iniciativa privada. $\mathrm{O}$ sistema tributário também poderia ser empregado para alterar o regime de posse da terra combinado com medidas diretas de fracionamento da propriedade, que evitem tanto os latifúndios improdutivos quanto a pulverização da terra em minúsculos lotes antieconômicos. ${ }^{9}$

O planejamento também deveria guiar a introdução de progresso técnico e evitar o desequilíbrio externo, rompendo com a deterioração dos termos de troca. A deterioração é vista aqui por uma nova perspectiva, envolvendo a técnica produtiva e as formas de consumo. ${ }^{10}$ Observa-se que as novas formas de produção diminuem a participação dos produtos primários na renda real da população, pois permitem a obtenção de uma variedade cada vez maior de produtos industriais a partir da mesma quantidade de matérias-primas, melhorando e diversificando seu uso, além de substituí-las diretamente por processos sintéticos. Pelo lado da demanda, o crescimento da renda, acima de certo limite, tende a diversificar o consumo, orientado para os artigos industrializados.

Isso é, o progresso técnico faz com que a elasticidade-renda da demanda por bens primários seja menor do que a unidade e os aumentos de renda dos países centrais sejam somente em parte transformados em importações primárias. Prebisch ressalta que, em virtude desse comportamento da demanda, se os países latino-americanos se restringissem a crescer com base na exportação, teriam obrigatoriamente que crescer menos do que os países centrais. Daí o autor concluir, mais uma vez, pela necessidade dinâmica da industrialização. No entanto, esta deve ser coordenada com uma expansão compatível das exportações, para que não haja desequilíbrio externo, uma vez que requer maior importação de bens de capital. ${ }^{11}$

9 “[...] essa forma de posse e o alto valor da terra [...] tornam difícil o acesso do solo para os agricultores sem terra, e estes se veem forçados a investir seus recursos limitados em frações de terra pequenas demais para gerar um padrão de vida mais alto que o do camponês assalariado, que é muito precário na maioria dos países. Daí o espetáculo singular da pulverização da terra em numerosíssimos lotes antieconômicos, que representam uma pequena parte da superfície total, em contraste com um número exíguo de proprietários que abarcam a maior parte da terra disponível." (PREBISCH, [1951] 2011, p. 294).

10 Tateando explicações teóricas para a observação empírica da deterioração dos termos de troca, o autor apresenta diferentes versões da questão. Tais versões são analisadas de forma exaustiva em Rodríguez (1981, 2009).

${ }^{11}$ Uma proposta de desenvolvimento equilibrado entre industrialização para o mercado interno e produção primária para exportação muito próxima das formulações contemporâneas de Nurkse ([1953] 1969). 
Na consecução de um programa de desenvolvimento que busque alcançar o máximo de renda real, ou seja, de bens e serviços à disposição da população, Prebisch aponta duas questões para a aplicação dos fatores produtivos: empregá-los para aumentar as exportações e a capacidade de importar, ou empregá-los para aumentar a produção de consumo interno; em seguida, uma vez alcançada essa proporção ótima, caberia decidir o que produzir internamente.

Na primeira questão, o autor lembra que o volume de exportações primárias depende, antes de tudo, do nível de renda dos países centrais e do grau de protecionismo adotado. Uma tentativa unilateral de expandir a quantidade exportada geraria maior deterioração dos preços, podendo acarretar perdas reais. Assim, conviria utilizar de forma alternativa os fatores produtivos, direcionando-os para a indústria, mesmo que esta apresente custos de produção superiores aos artigos similares importados. O que expressa, mais uma vez, a tomada de posição do autor em favor da burguesia industrial latinoamericana em sua disputa com os agroexportadores e também no conflito distributivo com os trabalhadores, base do mercado interno de consumo.

Na segunda questão, trata-se de saber em que tipo de produção investir para obter a maior renda real possível. Aqui o autor introduz o conceito de produtividade marginal social, afirmando que o capital deve ser aplicado de forma que gere o máximo de produção, até que se igualem as produtividades marginais das diferentes aplicações. O critério deveria ser, portanto, o da produtividade, e não o do custo comparativo. Ainda assim, algumas produções podem ser convenientes, mesmo com baixa produtividade, quando diminuam a vulnerabilidade da economia às flutuações cíclicas do comércio, evitando o desequilíbrio externo.

Esquematicamente exposta, a tese de desenvolvimento econômico apresentada nesta seção é a seguinte. As atividades de exportação dos países latino-americanos são insuficientes para absorver o aumento da população ativa disponível, em virtude de seu crescimento vegetativo e do progresso técnico. A industrialização, antes de mais nada, desempenha o papel dinâmico de absorver diretamente a população ativa excedente e de estimular outras atividades, inclusive a agricultura de consumo interno, a fim de que elas contribuam para o mesmo objetivo. Desse modo, por meio do progresso técnico e da industrialização, vai aumentando a renda global e melhorando a renda per capita. À medida que a renda vai aumentando dessa maneira e que se modifica a composição da demanda, é indispensável ir transformando a composição das importações e desenvolvendo a produção substitutiva interna, para que outras importações possam crescer intensamente.

Se esse reajuste das importações não for cumprido em medida suficiente, o crescimento da renda se manifestará na tendência ao desequilíbrio externo: as importações tenderão a crescer mais que a capacidade de importar. (PREBISCH, [1951] 2011, p. 278) 
Nessa linha de argumentação, a industrialização substitutiva, embora entendida como uma necessidade dinâmica para o crescimento das economias periféricas, apresenta especificidades que impedem sua expansão espontânea, demandando o planejamento estatal. Outro ponto destacado pelo autor refere-se ao desemprego tecnológico gerado pela introdução de técnicas produtivas intensivas em capital e poupadoras de mão de obra. Afirma que o progresso técnico foi orientado pelos países centrais no duplo sentido de aumentar o volume da produção e economizar mão de obra, e que a indivisibilidade dos equipamentos em que se materializa impede combinações mais favoráveis à disponibilidade de fatores dos países periféricos, com abundância de mão de obra e escassez de capital.

No processo de extensão da técnica produtiva na economia, deve ser ponderada a capacidade de absorção de trabalhadores, distinguindo-se entre o interesse do empresário e o interesse geral. Do ponto de vista do empresário, pode ser vantajoso introduzir novos processos que reduzam o custo de produção e aumentem seu lucro, mesmo que diminua sua capacidade de absorver trabalhadores. Já do ponto de vista do interesse geral, sendo o capital escasso, não há possibilidade de generalizar tais processos e, ao mesmo tempo, absorver a mão de obra excedente. Assim, compete ao Estado coordenar a introdução de tecnologia na produção para que não se eleve a densidade de capital acima do que convém para alcançar o pleno emprego.

Com essa proposta, Prebisch expõe a contradição presente em seu pensamento, e em grande parte das formulações da Cepal, entre a defesa persistente dos interesses da burguesia industrial e uma suposta autonomia do Estado para restringir a iniciativa privada, seja na introdução de novas tecnologias ou na adoção de formas sofisticadas de consumo. Levanta algumas questões pontuais em favor dos trabalhadores, imersas numa construção toda em função da consolidação do poder burguês. Alinhando-se e fundamentando as políticas características da América Latina nos anos 1950, com seus governos de legitimação da hegemonia da burguesia industrial, defende que somente a industrialização aumentaria os salários e o padrão de vida dos trabalhadores.

\section{CONCLUSÃO}

Tendo a América Latina como ponto de observação, Prebisch e a Cepal caminharam num sentido de superação da perspectiva linear da história, especialmente com a conceituação do sistema centro-periferia e do subdesenvolvimento. Está aí a importância maior da crítica ao falso sentido de universalidade teórica da economia do desenvolvimento. Com o conceito de sistema centro-periferia, Prebisch produziu uma primeira distinção entre as economias nacionais no sistema mundial - embora ainda 
atrelada à ideia de progresso -, subsidiando uma ação afirmativa das burguesias industriais latino-americanas em ascensão.

Consequentemente, Prebisch faz uma contundente crítica à política de desenvolvimento promovida pelos EUA na região, pois o caráter universal e genérico do receituário apresentado aos países ditos atrasados é rechaçado enquanto forma concreta de intervenção na realidade. Embora a Cepal, de fato, faça parte da estrutura institucional de organismos multilaterais destinados a coordenar o mundo capitalista sob hegemonia dos EUA, é preciso reconhecer que a comissão, em seus primeiros anos, exerceu um contraponto às teses e políticas mais alinhadas à expansão do poder estadunidense.

Prebisch, assim como a economia do desenvolvimento tradicional, combina elementos de análise clássicos e neoclássicos. No entanto, pode-se constatar sua tentativa de crítica interna à teoria neoclássica e, principalmente, sua contraposição à política comercial dos EUA e à inserção subordinada da América Latina na divisão internacional do trabalho. Assim, recorre aos conceitos neoclássicos - por exemplo, elasticidade-renda da demanda, produtividade marginal, fatores e funções de produção etc. - para questionar a convergência de rendas através da especialização produtiva; ou o princípio da substituição dos fatores de produção de acordo com sua disponibilidade; ou ainda o equilíbrio com pleno emprego e a mobilidade de fatores na economia mundial. Restringe-se, contudo, à crítica keynesiana e sua teoria dos ciclos, sem avançar para uma crítica radical da teoria neoclássica ou para um rompimento com a visão de mundo burguesa sobre o conflito distributivo capital-trabalho.

Baseando-se na dinâmica cíclica da economia mundial, observou as consequências distintas das flutuações cíclicas para o centro e a periferia, formalizando uma crítica à convergência dos níveis de renda dos países, concluindo que havia uma transferência dos frutos do progresso técnico da periferia para o centro, via deterioração dos termos de troca. Esse argumento foi a força motriz que subsidiou uma postura política de negação do modelo primário-exportador com especialização produtiva, criticando a divisão internacional do trabalho e legitimando a industrialização periférica comandada pela burguesia industrial latino-americana.

\section{REFERÊNCIAS}

BARBOSA, A. O anti-herói desenvolvimentista. Revista Novos Estudos Cebrap, ed. 94, v. 31, n. 3, p. 217-229, 2012.

BIELSCHOWSKY, R. Cinquenta anos de pensamento na Cepal: uma resenha. In: BIELSCHOWSKY, R. (Org.). Cinquenta anos de pensamento na Cepal. São Paulo: Record, 2000a. p. 13-68. 
BIELSCHOWSKY, R. Pensamento econômico brasileiro: o ciclo ideológico do desenvolvimentismo. 4. ed. Rio de Janeiro: Contraponto, [1988] 2000b.

BIELSCHOWSKY, R. Prebisch e Furtado. In: PREBISCH, R. O manifesto latino-americano e outros ensaios. Rio de Janeiro: Contraponto; Centro Internacional Celso Furtado, 2011. p. 7-14.

BORJA, B. A formação da teoria do subdesenvolvimento de Celso Furtado. Tese (Doutorado em Economia Política Internacional) - Instituto de Economia, Universidade Federal do Rio de Janeiro, Rio de Janeiro, 2013.

COUTO, J. M. O pensamento desenvolvimentista de Raúl Prebisch. Economia e Sociedade, v. 16, n. 1, p. 45-64, 2007.

FONSECA, P. C. D. Os dois “Prebischs". Economia e Sociedade, v. 20, n. 3, p. 695-700, 2011.

FURTADO, C. Características gerais da economia brasileira. Revista Brasileira de Economia, v. 4, n. 1, p. 7-37, 1950.

FURTADO, C. A fantasia organizada. In: FURTADO, C. Obra autobiográfica de Celso Furtado. Rio de Janeiro: Paz e Terra, [1985] 1997. Vol. I. p. 87-359.

FURTADO, C. Formação econômica do Brasil. 31. ed. São Paulo: Companhia Editora Nacional, [1959] 2003.

GURRIERI, A. A economia política de Raúl Prebisch. In: PREBISCH, R. O manifesto latinoamericano e outros ensaios. Rio de Janeiro: Contraponto; Centro Internacional Celso Furtado, [1982] 2011. p. 15-92.

NURKSE, R. Alguns aspectos internacionais do desenvolvimento econômico. In: AGARWALA, A.; SINGH, S. (Orgs.). A economia do subdesenvolvimento. Rio de Janeiro: Forense, [1953] 1969. p. 263-277.

PREBISCH, R. Cinco etapas de mi pensamiento sobre el desarrollo. El Trimestre Económico, v. 50, n. 198, p. 1077-1096, 1983.

PREBISCH, R. Crescimento, desequilíbrio e disparidades: interpretação do processo de desenvolvimento econômico. In: PREBISCH, R. O manifesto latino-americano e outros ensaios. Rio de Janeiro: Contraponto; Centro Internacional Celso Furtado, [1950] 2011. p. 153-245.

PREBISCH, R. O desenvolvimento econômico da América Latina e alguns de seus principais problemas. In: PREBISCH, R. O manifesto latino-americano e outros ensaios. Rio de Janeiro: Contraponto; Centro Internacional Celso Furtado, [1949] 2011. p. 95-151.

PREBISCH, R. Prefácio. In: RODRÍGUEZ, O. Teoria do subdesenvolvimento da Cepal. Rio de Janeiro: Forense-Universitária, 1981. p. 7-12.

PREBISCH, R. Problemas teóricos e práticos do crescimento econômico. In: PREBISCH, R. O manifesto latino-americano e outros ensaios. Rio de Janeiro: Contraponto; Centro Internacional Celso Furtado, [1951] 2011. p. 247-297.

RODRÍGUEZ, O. O estruturalismo latino-americano. Rio de Janeiro: Civilização Brasileira, 2009.

RODRÍGUEZ, O. Teoria do subdesenvolvimento da Cepal. Rio de Janeiro: Forense Universitária, 1981.

SERRANO, F; MEDEIROS, C. O desenvolvimento econômico e a retomada da abordagem clássica do excedente. Revista de Economia Política, v. 24, n. 2, p. 238-256, abril/junho 2004. 